\title{
Adapting the First Aid education and response to the COVID-19 pandemic crisis
}

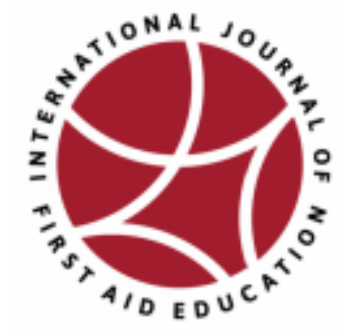

Spreading First Aid knowledge and conducting trainings must always be ongoing in all times and should never be stopped, not even during the current pandemic crisis or other crises, given the fact that during crises, accidents continue to happen and people continue to get injured, accordingly the need for first aid response remains critical. Moreover, in case of exhaustion of the official health systems (which is very likely to occur, especially in fragile contexts) the need for well-trained First Aid and prehospital care providers to support the health system will be greater, which goes in the same line with the approach of not stopping First Aid education procedures. Of course, the current situation forces all of us to adopt mitigation and adaptation processes in order to avoid having new victims of COVID-19 among the First Aid providers and/or emergency responders.

In support of First Aid training institutes such as Red Cross and Red Crescent National Societies, in mitigation for the current outbreak, this technical guidance note was developed as a suggestion for consideration:

\section{Adapting the curriculum:}

$>$ Donning and doffing should be an integral part of the First Aid curriculum.

$>$ A special chapter about viruses such as COVID-19 should be developed and included in the First Aid curriculum containing simple information about the signs \& symptoms, modes of transmission, the severity, ways of enhancing personal protection \& prevention (PPE) (Ref. WHO), and how to develop a customized response to suspected cases as per the context ( Ref. Health authorities in each country).

$>$ Additional chapter on sterilization and disinfectant materials which could be used to disinfect tools, materials, personal belongings, and First Aid equipment and means of transport ( cars, Tuk-Tuks, boats, carts, etc.), and those to be used on the hands and bodies of First Aid providers.

$>$ Appropriate waste management of the contaminated PPE should be focused on during the training to cover education about how to avoid cross contamination. 
$>$ In the same regard, the chapter of basic Psychological support should be further focused on, with special attention on providing such assistance to COVID-19 suspected patients and their relatives.

\section{Adapting the response}

While responding to accidents, moving the crowds away from the scene and patient is of even greater importance.

$>$ Initial assessment should begin from a distance of at least 6 feet from the patient, if possible.

$>$ Respiration assessment steps (look, listen, and feel) should depend mainly on (Look), to minimize closer contact with the patient.

$>$ In case of cardiac arrest, it is highly advisable to encourage hands-only CPR, as it is proved and confirmed by the AHA to have closer success rate to the conventional CPR.

$>$ Similarly, in case of drowning and choking persons who lost consciousness, hands only CPR should be utilized.

$>$ It is advised to deal with every patient as a suspected patient of COVID-19: face mask should be applied to all patients, and until the mask is on the patient's face, contact should be kept to minimum.

$>$ During transportation, number of first aiders should be kept to minimum (for example 2 first aiders to hold the stretcher instead of 4), immediate disinfection of the stretcher used in transportation should be done after handing the patient to EMS/ hospital.

$>$ In case of patient transportation in a private vehicle/ ambulance, the number of people in the patient compartment (including providers and relatives) should be limited in order to minimize possible exposure, and immediate disinfection of the vehicle / ambulance should be performed afterwards.

$>$ In all instances, all first aid providers and emergency responders should avoid touching their faces while working.

\section{Adapting the mode of education:}

Following the recommendations of the WHO regarding social distancing and avoiding the crowds, practical alternatives to the classic "classroom" First Aid courses or seminars should be thought of. In fact, with the evolving technological methods, several e-learning alternatives already exist. The following options are some examples where online platforms can be used:

If the first aid training provider has its own learning platform, they can upload the First Aid lessons on it, and encourage their staff and volunteers, as well as the public, to follow them. 
$>$ Using of free hosting social media sites ( for example, Youtube or Facebook) to upload videos and promote messages.

$>$ With obtaining the necessary permission, some videos produced by Red Cross or Red Crescent National Societies could be used in this regard (British RC for example).

> Using the International Federation of Red Cross/ Red Crescent (IFRC) developed videos and courses.

$>$ Using live streams on some applications like Skype, Webex, $\underline{\text { Zoom }}$

$>$ Uploading the course materials on learning platforms like: Udemy, Future learn

Using the free enabling platforms like: easy class, google classroom

Each platform has its own pros and cons, some allow only live streaming, some may charge for certain services, some of them enable the course provider to set up tests, record the tests results, and store the trainees' data for future calls. Each training provider should make their choice according to their and training policy and objectives.

At the end, the main objective is to continue all the efforts aiming at saving lives and assisting the most vulnerable in times of crisis, while putting the safety of the staff, volunteers, emergency responders, and all First Aid providers at the heart of the whole process.

Tamer Ahmad Ramadan, MSc, Master's International Cooperation and Humanitarian Aid, BDS

First aid delegate

International Committee of the Red Cross

\section{$\underline{\text { References }}$}

WHO official website, updates and recommendations.

$\underline{\text { Rational use of personal protective equipment (PPE) for coronavirus disease (COVID-19) }}$

CDC recommendations and guidelines.

AHA 2019 guidelines. 